\title{
A resurrection of the Haber-Weiss reaction
}

\author{
Willem H. Koppenol (10) ${ }^{1,2 \otimes}$
}

ARISING FROM Zhao et al. Nature Communications https://doi.org/10.1038/s41467-020-20071-w (2020)

A s Elimelech et al. ${ }^{1}$ point out, there is a legitimate need for a method that produces singlet dioxygen $\left({ }^{1} \Delta_{\mathrm{g}} \mathrm{O}_{2}\right)$ efficiently, because this species plays a role in a research fields like environmental science and biochemistry. They ${ }^{1}$ describe a flow-through filtration process whereby singlet dioxygen is generated electrochemically. The mechanism proposed by Elimelech et al. ${ }^{1}$ for its production is based on the reduction of hydrogen peroxide by superoxide, the infamous Haber-Weiss reaction, and is therefore incorrect. Furthermore, the evidence for formation of singlet dioxygen is questionable.

The mechanism, shown in Fig. 4 of that publication ${ }^{1}$, starts with reduction of $\mathrm{O}_{2}$ at the cathode to $\mathrm{O}_{2}{ }^{--}$and $\mathrm{H}_{2} \mathrm{O}_{2} \cdot \mathrm{H}_{2} \mathrm{O}_{2}$ is, of course, also formed by the spontaneous disproportionation of $\mathrm{O}_{2}{ }^{\bullet-}$. Subsequently, ${ }^{1} \Delta_{\mathrm{g}} \mathrm{O}_{2}$ is proposed to be produced via reaction 1:

$$
\mathrm{O}_{2}^{\bullet-}+\mathrm{H}^{+}+\mathrm{H}_{2} \mathrm{O}_{2} \rightarrow{ }^{1} \Delta_{\mathrm{g}} \mathrm{O}_{2}+\mathrm{HO}^{\bullet}+\mathrm{H}_{2} \mathrm{O}
$$

This reaction became known as the Haber-Weiss reaction (with ${ }^{1} \Delta_{\mathrm{g}} \mathrm{O}_{2}$ or ${ }^{3} \Sigma_{\mathrm{g}}{ }^{-} \mathrm{O}_{2}$ ) and was proposed in $1931^{2}$. It proceeds with a rate constant of at best $1 \mathrm{M}^{-1} \mathrm{~S}^{-13}$, and cannot compete ${ }^{4}$ with the rapid and spontaneous ${ }^{5}$ disproportionation of $\mathrm{O}_{2}{ }^{\bullet-}$.

Elimelech et al. cite my 1976 publication ${ }^{6}$ in support for formation of ${ }^{1} \Delta_{\mathrm{g}} \mathrm{O}_{2}$. Indeed, I wrote that reaction (1) is thermodynamically possible. However, the standard Gibbs energies of formation of $\mathrm{HO}^{\bullet}$ and $\mathrm{O}_{2}{ }^{--}$have been determined more accurately since then ${ }^{7}$, with the result that reaction 1 with $\mathrm{O}_{2}$ in the singlet state is thermodynamically not possible ${ }^{3,8}$.

Elimelech et al. report that insignificant amounts of $\mathrm{HO}^{\bullet}$ were detected. This should have led them to reject Reaction 1, because for every ${ }^{1} \Delta_{\mathrm{g}} \mathrm{O}_{2}$ also one $\mathrm{HO}^{\bullet}$ is formed. Could it be that the terephthalate concentration these authors used to detect $\mathrm{HO}^{*}$ was insufficient? If ${ }^{1} \Delta_{\mathrm{g}} \mathrm{O}_{2}$ was detected with micromolar concentrations of furfuryl alcohol, then $\mathrm{HO}^{\bullet}$ should also have been seen, given that the rate constants of ${ }^{1} \Delta_{\mathrm{g}} \mathrm{O}_{2}$ and $\mathrm{HO} \mathrm{O}^{\bullet}$ with furfuryl alcohol and terephthalate are similar, that terephthalate was present in millimolar concentrations, and that unlike $\mathrm{HO}^{\bullet},{ }^{1} \Delta_{\mathrm{g}} \mathrm{O}_{2}$ is quenched in water at a rate of $2.7 \cdot 10^{5} \mathrm{~s}^{-1}$. Although irrelevant at this stage, the notion that $\mathrm{HO}^{\bullet}$ reacts with terephthalate to yield hydroxyterephthalate is incorrect. Instead, an adduct is formed that needs to be oxidised to yield hydroxyterephthalate.
The authors base their conclusion that ${ }^{1} \Delta_{\mathrm{g}} \mathrm{O}_{2}$ is formed also on the reaction of the latter with 2,2,6,6-tetramethylpiperidine, but do not discuss the possibility that this compound may be oxidised at the anode and then yields 2,2,6,6-tetramethyl-4-piperidinol- $N$ oxyl after reaction with $\mathrm{O}_{2}{ }^{10}$. Formation of any products from ${ }^{1} \Delta \mathrm{gO}_{2}$ would have been enhanced in $\mathrm{D}_{2} \mathrm{O}$ where ${ }^{1} \Delta \mathrm{gO}_{2}$ lives much longer, or decreased by addition of a quencher, such as $1,4-$ diazobicyclo[2.2.2] octane.

Thermodynamically, a simpler route to ${ }^{1} \Delta_{\mathrm{g}} \mathrm{O}_{2}$ could be the oxidation of $\mathrm{O}_{2}{ }^{-}-$to ${ }^{1} \Delta_{\mathrm{g}} \mathrm{O}_{2}$ at the anode, because the electrode potential of the couple ${ }^{1} \Delta_{\mathrm{g}} \mathrm{O}_{2}(\mathrm{aq}) / \mathrm{O}_{2}{ }^{-}$is $+0.81 \mathrm{~V}^{11}$. In contrast, the spontaneous disproportionation of $\mathrm{O}_{2}{ }^{-}$is not an alternative, as the yield of ${ }^{1} \Delta_{\mathrm{g}} \mathrm{O}_{2}$ varies from not detectable to extremely low, as recently reviewed ${ }^{8}$.

If we assume that is ${ }^{1} \Delta_{\mathrm{g}} \mathrm{O}_{2}$ formed, we may ask: how much? Given the consumption of furfuryl alcohol, the rate constant of the reaction of this compound with ${ }^{1} \Delta_{\mathrm{g}} \mathrm{O}_{2}$, the quenching rate constant for ${ }^{1} \Delta_{\mathrm{g}} \mathrm{O}_{2}$ in water ${ }^{9}$, and the flow rate, one arrives at a low nanomolar steady-state concentration of ${ }^{1} \Delta_{\mathrm{g}} \mathrm{O}_{2}$. This calculation also shows that only $1.8 \%$ of all ${ }^{1} \Delta_{\mathrm{g}} \mathrm{O}_{2}$ reacts with furfuryl alcohol.

Experimental conditions and nomenclature need to be discussed too. Elimelech et $\mathrm{al}^{1}$. use scavengers at a single concentration, with the exception of terephthalate which was used at two concentrations. These experiments do not prove that ${ }^{1} \Delta_{\mathrm{g}} \mathrm{O}_{2}$, $\mathrm{O}_{2}{ }^{\bullet-}, \mathrm{H}_{2} \mathrm{O}_{2}$, and $\mathrm{HO}^{\bullet}$ are formed, because such a non-dosedependent approach only gives an indication. The authors refer to these scavengers as specific for a particular species. Since $\mathrm{HO}^{\circ}$ reacts with nearly everything at high rates, such terminology is inappropriate. Indeed, $\mathrm{N}_{3}{ }^{-}$quenches ${ }^{1} \Delta_{\mathrm{g}} \mathrm{O}_{2}$, but it also reacts with $\mathrm{HO}^{\circ}$, as do $p$-benzoquinone and catalase. It would have been beneficial if the authors had consulted the Solution Kinetics Database of the National Institute of Standards and Technology ${ }^{12}$ for the relevant rate constants. The description of ${ }^{1} \Delta \mathrm{gO}_{2}$ as "possessing an empty $\pi^{*}$ orbital"1 is simplistic ${ }^{13}$. When electrofiltration was carried out to remove substances, temperature and $\mathrm{pH}$ were not mentioned. The word "quenching" is used as a synonym of "scavenging", which is incorrect ${ }^{14}$. The term ROS for Reactive Oxygen Species, although widespread, is misleading as neither $\mathrm{O}_{2}{ }^{--}$nor $\mathrm{H}_{2} \mathrm{O}_{2}$ are reactive, as argued before ${ }^{15}$. A study of the thermodynamics and kinetics of reactions of small, shortlived, oxygen-containing species will illustrate this.

\footnotetext{
${ }^{1}$ Emeritus, Swiss Federal Institute of Technology, Zürich, Switzerland. ${ }^{2}$ Present address: Schwändibergstrasse 25,8784 Braunwald, Switzerland.

凶email: koppenol@inorg.chem.ethz.ch
} 
In summary, it is not impossible that Elimelech et al. produced singlet dioxygen, but certainly not via the oxidation of $\mathrm{O}_{2}{ }^{--}$by $\mathrm{H}_{2} \mathrm{O}_{2}$.

Received: 22 March 2021; Accepted: 18 November 2021;

Published online: 19 January 2022

\section{References}

1. Zhao, Y. et al. Janus electrocatalytic flow-through membrane enables highly selective singlet oxygen production. Nat. Commun. 11, 6228 (2020).

2. Haber, F. \& Willstätter, R. Unpaarigheit und Radikalketten im Reaktionsmechanismus organischer und enzymatischer Vorgänge. Chem. Ber. 64, 2844-2856 (1931).

3. Koppenol, W. H. The Haber-Weiss cycle - 70 years later. Redox Rep. 6 229-234 (2001).

4. Barb, W. G. et al. Reactions of ferrous and ferric ions with hydrogen peroxide. Nature 163, 692-694 (1949).

5. Bielski, B. H. J. et al. Reactivity of $\mathrm{HO}_{2} / \mathrm{O}_{2}{ }^{-}$radicals in aqueous solution. $J$. Phys. Chem. Ref. Data 14, 1041-1100 (1985).

6. Koppenol, W. H. Reactions involving singlet oxygen and the superoxide anion. Nature 262, 420-421 (1976).

7. Armstrong, D. A. et al. Standard electrode potentials involving radicals in aqueous solution: inorganic radicals. Pure Appl. Chem. 87, 1139-1150 (2015).

8. Filipovic, M. R. \& Koppenol, W. H. The Haber-Weiss reaction - The latest revival. Free Radic. Biol. Med. 145, 221-222 (2019).

9. Appiani, E. et al. Aqueous singlet oxygen reaction kinetics of furfuryl alcohol: effect of temperature, $\mathrm{pH}$, and salt content. Environ. Sci.: Process. Impacts 19 , 507-516 (2017).

10. Nardi, G. et al. Scope and limitations of the TEMPO/EPR method for singlet oxygen detection: the misleading role of electron transfer. Free Radic. Biol. Med. 77, 64-70 (2014)

11. Koppenol, W. H., Stanbury, D. M. \& Bounds, P. L. Electrode potentials of partially reduced oxygen species, from dioxygen to water. Free Radic. Biol. Med. 49, 317-322 (2010).

12. National Institute of Science and Technology, NIST Chemical Kinetics Database, Standard Reference Database 17, Version 7.0, Release 1.4.3. http:// kinetics.nist.gov/kinetics/index.jsp (2009).
13. Kasha, M. \& Khan, A. U. The physics, chemistry, and biology, of singlet molecular oxygen. Ann. NY Acad. Sci. 171, 5-23 (1970).

14. McNaught A. D. and Wilkinson, A. Compendium of Chemical Terminology. IUPAC Recommendations, 2 ed. (Blackwell Science, Oxford, 1997).

15. Koppenol, W. H. \& Hider, R. C. Iron and redox cycling. Do's and don'ts. Free Radic. Biol. Med. 133, 3-10 (2019).

\section{Author contributions}

This is a paper was conceived and written by a single author.

\section{Competing interests}

The author declares no competing interests.

\section{Additional information}

Correspondence and requests for materials should be addressed to Willem H. Koppenol.

Peer review information Nature Communications thanks the anonymous reviewers for their contribution to the peer review of this work.

Reprints and permission information is available at http://www.nature.com/reprints

Publisher's note Springer Nature remains neutral with regard to jurisdictional claims in published maps and institutional affiliations.

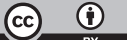

Open Access This article is licensed under a Creative Commons Attribution 4.0 International License, which permits use, sharing, adaptation, distribution and reproduction in any medium or format, as long as you give appropriate credit to the original author(s) and the source, provide a link to the Creative Commons license, and indicate if changes were made. The images or other third party material in this article are included in the article's Creative Commons license, unless indicated otherwise in a credit line to the material. If material is not included in the article's Creative Commons license and your intended use is not permitted by statutory regulation or exceeds the permitted use, you will need to obtain permission directly from the copyright holder. To view a copy of this license, visit http://creativecommons.org/ licenses/by/4.0/

(C) The Author(s) 2022 